\title{
Designing Error Detection Prompts And PeEr FeedBack FOR PHYSICS ClASSROOMS
}

\author{
Elizabeth Charles ${ }^{1}$, Kevin Lenton ${ }^{2}$, Rhys Adams ${ }^{2}$, Michael Dugdale ${ }^{3}$, Nathaniel Lasry ${ }^{3}$, Yann Brouillette ${ }^{2}$, \\ Phoebe Jackson ${ }^{3}$, Chao Zhang ${ }^{4}$ \\ ${ }^{1}$ Dawson College, ${ }^{2}$ Vanier College, ${ }^{3} \mathrm{John}$ Abbott College, ${ }^{4} \mathrm{McGill}$ University \\ echarles@dawsoncollege.qc.ca, adamsr@vaniercollege.qc.ca
}

\begin{abstract}
We examine the design of error detection prompts which scaffold peer-feedback as a corrective process, rather than an error-identification task. After designing a series of these prompts, they were given to a class of students in an introductory physics course (treatment group). Students in the treatment group, in comparison to the control group, 1) were more successful at correctly identifying errors and providing more meaningful feedback to a fictional classmate, and 2) wrote more, and explained physics better on final exam questions. In addition, several students adopted a mentoring (tutor-tutee) identity when writing feedback.
\end{abstract}

Keywords: Error detection prompts, Peer feedback, Physics education

\section{INTRODUCTION}

Peer feedback, as a component of student-centred instruction (aka Active Learning), is firmly grounded in social constructivist learning theories. It can be viewed as involving the joint construction of knowledge through exchange of dialog $[1,2]$ and learning from the mutual reflection and judgement on performance [3]. However, the cognitive and metacognitive skills required to use feedback, as an effective tool for knowledge construction, are not automatic for all students and need to be learned [4]. In short, as part of an active learning approach, it is reasonable to believe students can benefit from practicing peer review.

Peer review is a normative part of scientific practice and scholarship. Becoming a scientist, the process of enculturation, means adopting the stance that receiving and using feedback is an essential part of improvement. In turn, giving feedback is important, signalling membership in the community. Arguably, engaging students in such activity is beneficial to their understanding of the epistemic forms of science and how scientific knowledge is generated.

This paper describes a design-based research (DBR) study focused on constructing a type of question that prompts peer feedback, based on detecting error(s) - i.e., error detection prompts (EDP). To do so, we use Hattie and
Timperley's [5] progressive feedback model, which describes four levels of detail learners can engage in when giving feedback: (1) task (content knowledge), (2) process, (3) self-regulation and (4) affect in which feedback is about evaluation of the person, and is not knowledge-based. We designed these error detection questions to focus on the levels of process and affect.

\section{CONTEXT}

Error detection as instruction has been used in math education [6] but less so in physics. Problem solving is a critical part in learning physics and a major skill required in the current curriculum competencies. A continuing issue is that students make the same conceptual mistakes when solving physics problems, they confuse the conceptual understanding (the why) and the procedural understanding (the how).

In this context, EDP are questions framed to look like typical answers from students, that contain conceptual mistakes. Students, in answering this question type, are expected to not only identify the mistake, but also to explain to others (peers) how to correct the error. These incorrect solutions reveal misconceptions teachers see frequently in answers to typical advanced level physics problems. In doing so, they reflect the procedural and conditional knowledge required for problem solving in the discipline. Lastly, our EDP added a scaffold to promote an affective response, we introduced a fictional student, Pat (as a gender-neutral name), who was the author of all the solutions that contained the errors.

When it comes to the content of the EDPs, we used the literature of common misconceptions in mechanics to validate our selection of topics from our own bank of examples of past student assessments. Common conceptual targets include: Force implicates acceleration (change in motion) and not velocity (or motion itself), distinguishing Newton's 3rd and 2nd Laws, defining vector directions relative to chosen axes, confusing torque and force, differentiating conservative and non-conservative forces, definition of the system in the context of impulse and momentum.

An example of an EDP and peer feedback question is shown in Figure 1. The problem is broken up into sections 
that allow students to narrow down where the error is exactly. The error in this case concerns the description of the motion in (5).

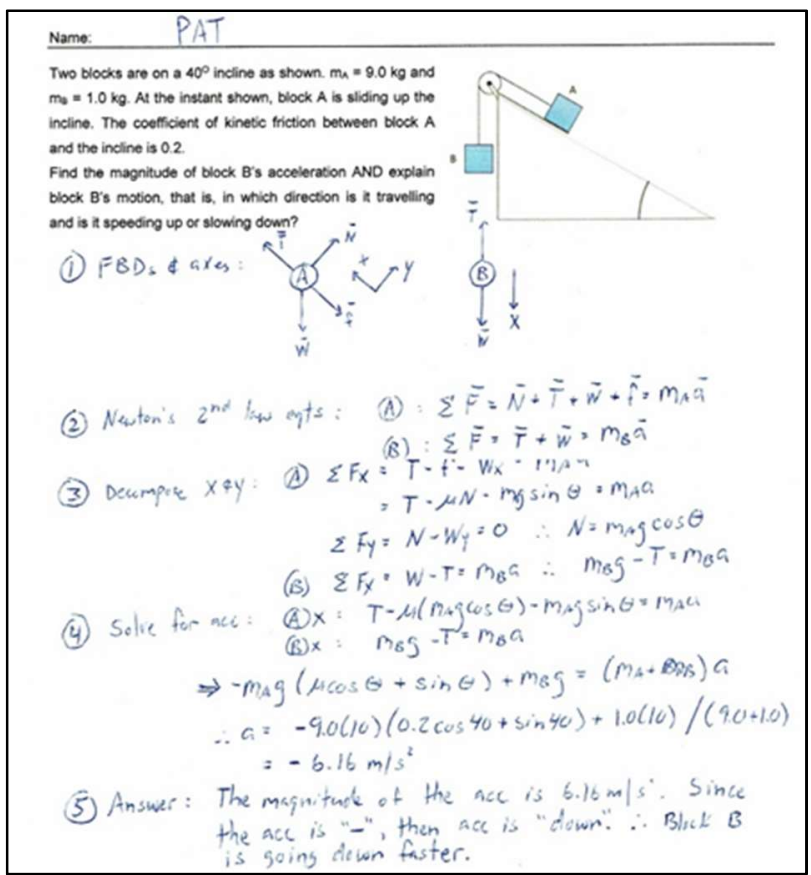

(a)

"Your best friend Pat has completed a quiz on dynamics and has a copy for you to review. The solution has one or more errors. If there is only one error, help Pat by stating where the error is found (parts 1-5). If there are multiple errors, state which is the most important error and justify your choice. Explain to Pat how the solution can be improved, or the error(s) resolved. Provide your response as if you are speaking to Pat; you want to be a good peer so provide constructive feedback."

(b)

Fig. 1. Example of an EDP and peer feedback question: (a) the error containing solution written by a fictional student, Pat; (b) instructions provided to students.

\section{METHODS}

A DBR approach uses mixed methods. Starting with a quasi-experimental design, we examined the impact of the first iteration of these EDP for their effectiveness at supporting students to provide better peer feedback. Two calculus-based mechanics physics sections, taught by different teachers at the same urban college, were selected. Both sections had similar pre-scores in the Force Concept Inventory (FCI; [7]).

The treatment group ( $\mathrm{N}=32)$, had four error-detection activities over the course of a month. The activities corresponded to the regular content sequence in the course.
They also had a short training in what makes for good peer feedback. The control section $(\mathrm{N}=30)$ did not have any error-detection activities, nor any practice or training in providing peer feedback, but followed a similar topic sequence and schedule.

Following the feedback training, both treatment and control groups were given the same error-detection and feedback activity (see Figure 1). The feedback quality was analyzed based on a teacher rubric. In addition to correctly answering the problem, the affective quality of the feedback was evaluated based on how personalized it was.

After, the treatment group continued with errordetection activities throughout the semester, completing nine in total; the control group did not receive further practice. Both groups were given common questions on the final exam.

The data collection included students' semester-long responses to the error-detection activities (in-class and online with myDALITE.org; [8]), as well as the final exam. The treatment group completed a survey about their perception of the EDPs and interviews were done with seven students.

\section{RESULTS AND DISCUSSION}

We begin with an analysis of error-detection and feedback activity shown in Figure 1. The feedback-quality rubric examined if students had correctly identified where the error was, what the nature of the error was, and how to correct the error, assigning either 1 if present and correct, or 0 . The affective quality was scored a 1 if the students made any reference directly to Pat, for instance, "Hi Pat" or "You did this wrong, Pat." The results are summarized in Table 1.

Table 1: Results of the error-detection and feedback activity.

\begin{tabular}{|c|c|c|c|}
\hline & & Control & Treatment \\
\hline \multirow{4}{*}{$\begin{array}{c}\text { Avg } \% \\
\text { Score }\end{array}$} & Where & 30 & 66 \\
\cline { 2 - 4 } & What & 27 & 63 \\
\cline { 2 - 4 } & How & 27 & 63 \\
\cline { 2 - 4 } & Affective & 40 & 81 \\
\hline
\end{tabular}

Not surprisingly, students who had more practice with EDP scored much better than those students who had not. The data also shows that students who identified where the error was, largely also identified what the error was and how to fix it. The treatment group was correct at rates about double that of the control group.

Regarding the affective scores, the high score for the treatment group is consistent with the early data collection, where we noted the affective prompt generated a social connection with the fictional classmate, Pat. Some students used language like "Hey Pat, since you're my good friend...", "good luck for next time. Your good friend..." This was particularly pronounced after the treatment group 
had a training on giving good feedback. This was also particularly notable compared to the control group, where most students responded as though writing to the teacher.

Globally, our results show little to no difference in physics knowledge and understanding, between the treatment and control group, based on the final exam. For problem-solving/numerical-based questions, the scores showed no statistical difference between students in the treatment and control groups. For questions prompting for feedback, such as in Figure 2, students in the treatment group gave more feedback to the process prompts (longer explanations) compared to the control, and their feedback used more correct and complete physics explanations (based on an expert rubric).

Below is a conceptual multiple-choice question. You can see a student's incorrect answer and rationale. Explain why the answer and rationale are incorrect. What is the correct answer and why?

A large truck collides head-on with a small compact car. The damage on the car is considerable whereas the truck has very little damage. During the collision:

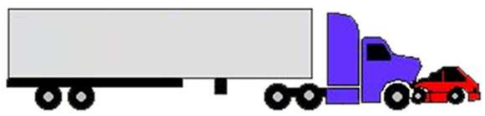

A) The truck undergoes a greater magnitude of impulse that that of the car.

B) The car undergoes a greater magnitude of impulse that that of the truck.

C) Both the truck and the car undergo the same magnitude of impulse.

D) The impulses cancel so neither undergoes any impulse.

STUDENT: The answer is 2 . Since the collision is more violent for the car, it had to undergo a greater change in momentum, hence, it undergoes a greater impulse.

Fig. 2. Common final exam question prompting for feedback.

Figure 3 shows the word density distribution as a function of word count for the question shown in Figure 2. The mean word count for the treatment group is 60.8 compared with 29.5 for the control group.

Each answer was coded based on a rubric identifying key criteria for scientific explanations [9], within the context of specific content. These five criteria are: (1) identification/naming of correct law, (2) statement explaining the law, (3) conditional constraints, (4) causal relationship, and (5) causal outcome. For example, the correct answer to question is choice C. An explanation reflecting all five criteria would contain something like: Due to Newton's third law (1), the force from the car on the truck and the force on the truck from the car are the same due (2), and the time applied will be the same on both as well (3). Therefore, the impulses [change in momentum] for each object will be equal and opposite (4). The truck may have less damage because its greater mass means it will experience a smaller acceleration (5).
Based on this rubric, the treatment group scored an average of $2.15 \pm 0.45$ of these features, whereas the control group scored an average of $0.74 \pm 0.39(95 \%$ confidence interval for both).

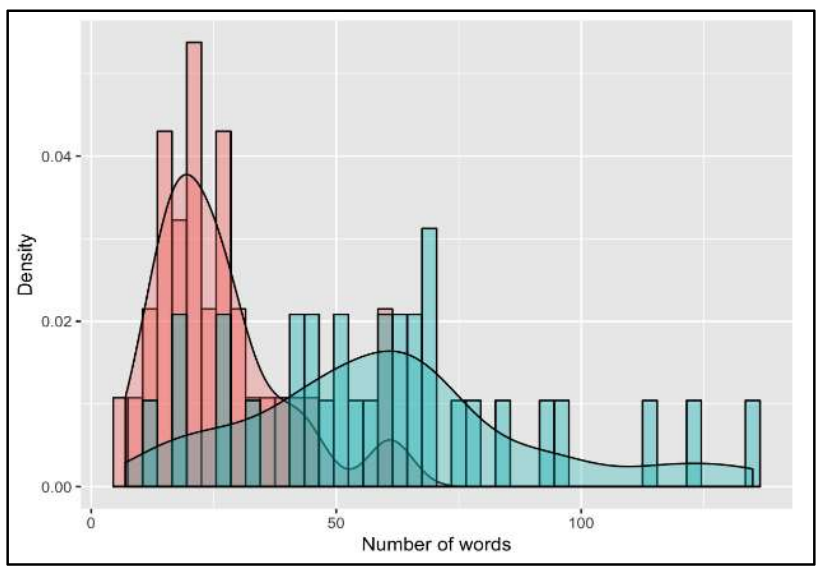

Fig. 3. The word density distribution as a function of word count on a final exam question prompting for feedback for the treatment (blue) and control (pink) groups.

Table 2 reports on the results of the survey completed by the treatment group. Question 1 was asked using a 5point Likert scale and is summarized here into no, yes and maybe. Questions 2 and 3 were yes/no questions. Overall, the students were positive about the approach and felt strongly that the process of explaining physics to someone else (i.e. Pat) helped them to learn physics.

Table 2: Survey results about students' engagement with error-detection activities and peer feedback (treatment group only)

\begin{tabular}{|c|c|c|c|}
\hline Question & No & Yes & Maybe \\
\hline $\begin{array}{c}\text { Q1: Have you learned to } \\
\text { provide better feedback? }\end{array}$ & $10 \%$ & $54 \%$ & $36 \%$ \\
\hline $\begin{array}{c}\text { Q2: Did giving "feedback" } \\
\text { and explaining to Pat help } \\
\text { you learn physics? }\end{array}$ & $18 \%$ & $82 \%$ & \\
\hline $\begin{array}{c}\text { Q3: Do you feel you made a } \\
\text { connection with Pat? }\end{array}$ & $46 \%$ & $54 \%$ & \\
\hline
\end{tabular}

Students were also encouraged to provide comments in the survey. Regarding question 2, students who answered affirmatively provided comments such as: "Yes, it did. It not only helped me with the structure of good solution, but it helped me be more aware of errors I could possibly make." Interestingly, some students who answered negatively felt that the error-detection activities were not challenging enough, hence were not helpful for their learning, "It wasn't a big challenge, so it didn't make me use all I was taught. Each problem had one or two mistake that were easy to detect." 
For question 3, students were more evenly divided regarding making a connection to their fictional classmate, Pat. However, their reasons varied, for example:

"Yes, Pat feels like a friend who you study with, trying to help him out. By helping Pat out, it improves my understanding of the topic, just like studying with someone."

"Yes, I have made a connection with Pat, whenever I hear his name, I get stressed out because I do not do well on his quizzes generally."

"No, and I don't think that providing feedback is very relevant as a type of quiz. I think that correcting his errors and understand them would be enough."

"Nooooo! ... this idiot making so many mistakes. But I think it's the best way of giving feedback if he wants to learn from his mistakes."

In post-intervention interviews, some students talked about Pat as though the fictional classmate were real. Such students reported a mentoring or tutor-tutee relationship: "I feel like a tutor", "I think he's helping me and I'm helping him", "I think he is more like a study partner." Important to note that two students reported a strong negative reaction to Pat, viewing "him" as annoying. Note they also attributed a gender.

\section{CONCLUSIONS}

By using EDP as part of a physics class, students in the treatment group practiced giving feedback to a fictional classmate and engaged with physics content. These students outperformed a control group in correctly identifying errors and providing more meaningful feedback to this fictional character. Students in the treatment group also wrote more and wrote better physics on final exam questions that prompted for feedback. Students were positive about the approach and felt strongly that the process of providing feedback helped them to learn physics. Last, some students adopted a mentoring tutortutee identity when writing feedback.

Students in the treatment group performed equally to the control group (as seen on the final exam), when presented with "traditional" problem solving questions but, strikingly, when these same treatment-group students were prompted to explain physics to the fictional Pat, they outperformed the control group. This success with the prompted questions is consistent with other research that shows the difficulty students have in regulating their attention, much like the fast and slow dual-cognitive processing being examined by physics education researcher Paula Heron and colleagues [10]. The fact that students, who are so successful when prompted to identify Pat's errors and to mentor him/her correctly, then fail to take their own advice, when unprompted, suggests we still have a lot to investigate about using EDP to support student learning.

\section{Acknowledgements}

The authors thank the Programme d'aide à la recherche sur l'enseignement et l'apprentissage (PAREA; grant PA2017-013), the Ministry of Education (MELS \& MERST) program, in the Province of Quebec.

\section{References}

[1] J. A. Hattie and G. C. Yates, "Using feedback to promote learning," in [Applying science of learning in education: Infusing psychological science into the curriculum] V. A. Benassi, C. E. Overson, \& C. M. Hakala (Eds.), Retrieved from the Society for the Teaching of Psychology, pp. 45-58, 2014. (http://teachpsych.org/ebooks/asle2014/index.php)

[2] N. Falchikov and J. Goldfinch, J, "Student peer assessment in higher education: A meta-analysis comparing peer and teacher marks." Review of educational research, vol. 70, no. 3, pp. 287-322, 2000.

[3] J. W. Strijbos and D. Sluijsmans, "Unravelling peer assessment: Methodological, functional, and conceptual developments." Learning and Instruction, vol. 20, no. 4, pp. 265-269, 2010.

[4] O. Poverjuc, V. Brooks and D. Wray, "Using peer feedback in a Master's programme: a multiple case study," Teaching in Higher Education, vol. 17, pp. 465477, 2012.

[5] J. Hattie and H. Timperley, "The power of feedback," Review of educational research, vol. 77, no. 1, pp. 81112, 2007.

[6] T. Heemsoth and A. Heinze, "Secondary school students learning from reflections on the rationale behind self-made errors: A field experiment," Journal of Experimental Education, vol. 84, no. 1, pp. 98-118, 2016.

[7] D. Hestenes, M. Wells and G. Swackhamer, "Force Concept Inventory," The Physics Teacher, vol. 30, pp. 141-158, 1992.

[8] E. S. Charles, N. Lasry, S. Bhatnagar, R. Adams, K. Lenton, Y. Brouillette, M. Dugdale, C. Whittaker and P. Jackson, "Harnessing peer instruction in- and out- of class with myDALITE," Proc. SPIE - Education and Training in Optics and Photonics (ETOP) Conference, (Québec City, Québec, Canada, May 22, 2019), 111430Z, 2019. https://doi.org/10.1117/12.2523778

[9] R. A. Duschl and J. Osborne, "Supporting and Promoting Argumentation Discourse in Science Education," Studies in Science Education, vol. 38, no. 1, pp. 39-72, 2002.

[10] P. R. Heron, "Testing alternative explanations for common responses to conceptual questions: An example in the context of center of mass," Physical Review Physics Education Research, vol. 13, no. 1, 010131, 2017. 